\title{
Dentate Granule Cells Are Essential for Kainic Acid-Induced Wet Dog Shakes but not for Seizures
}

\author{
L. Grimes, ${ }^{1}$ J. McGinty, ${ }^{2}$ P. McLain, ${ }^{3}$ C. Mitchell, ${ }^{4}$ H. Tilson, ${ }^{4}$ and J. Hong ${ }^{4}$ \\ 'Curriculum in Toxicology, University of North Carolina at Chapel Hill, North Carolina 27514, 2Department of Anatomy, East \\ Carolina University School of Medicine, Greenville, North Carolina $27858,{ }^{3}$ Chemical Pathology Branch, National Institute of \\ Environmental Health Sciences, and ${ }^{4}$ Laboratory of Behavioral and Neurological Toxicology, National Institute of \\ Environmental Health Sciences, National Institutes of Health, Research Triangle Park, North Carolina 27709
}

\begin{abstract}
The purpose of this study was to determine the role that dentate granule cells play in wet dog shakes (WDS), behavioral seizures, and hippocampal cell loss caused by systemic administration of kainic acid (KA). Rats were given bilateral injections of colchicine (COL) into the hippocampal formation to selectively lesion dentate granule cells. Two weeks later, they were injected subcutaneously with KA and were observed for WDS and seizures. Seizures were terminated with pentobarbital $2.5 \mathrm{hr}$ after KA injection, and the rats were killed $48 \mathrm{hr}$ later. The integrity of hippocampal cell populations and projections to the hippocampal formation from entorhinal cortex was assessed with radioimmunoassay and immunostaining for methionine-enkephalin (ME) and dynorphin (DYN) A, as well as with Timm and Nissl staining. Results indicate that $\mathrm{COL}$ injections eliminated KA-induced WDS, did not affect the latency to onset of seizures, and potentiated KA-induced cell loss in the CA3 region of hippocampus. COL lesions eliminated ME and DYN immunostaining of granule cells, but not ME immunostaining of entorhinal afferents to the dentate gyrus or Ammon's horn. These findings indicate that granule cells are an essential neuronal link in the expression of KA-induced WDS, but that seizures propagate along other pathways in the limbic system.
\end{abstract}

Temporal lobe epilepsy (TLE), which afflicts approximately half of adult epileptics (Gastaut et al., 1975), is characterized by tonic-clonic seizures that may include facial clonus with hypersalivation (Gastaut, 1980). At autopsy, patients suffering from TLE have pyramidal cell loss in the CA1 and CA3 sectors of Ammon's horn of the hippocampal formation (Dam, 1980). Kainic acid (KA), a cyclic analog of the excitatory amino acid glutamate, has been used to produce limbic seizures in experimental animals (Olney et al., 1974). The use of KA exposure as a model to TLE (Ben-Ari, 1985) has been justified by the nature of the resulting seizures, the patterns of cell loss (Nadler

Received Mar. 18, 1987; revised July 7, 1987; accepted July 8, 1987.

This work was supported by Training Grants 5-T32-ES-07126 (L.G.) and DA03982 (J.M.). We wish to thank the following for their excellent technical support: Amy Cooper, Jeffrey Simpson, Ronnie McLamb, John Peterson, and Sabreen Rahmaan. We also thank Larry Lazarus and Bill Wilson for a critical reading of this manuscript.

Correspondence should be addressed to Laura M. Grimes, Curriculum in Toxicology, 321 Faculty Laboratory Office Bldg. 231H, University of North Carolina at Chapel Hill, Chapel Hill, NC 27514.

Copyright (c) 1988 Society for Neuroscience $0270-6474 / 88 / 010256-09 \$ 02.00 / 0$ et al., 1978; Ben-Ari et al., 1980a, b; Lothman and Collins, 1981; Sloviter and Damiano, 1981a), and the spontaneous and recurrent seizures that begin 8-10 d after the initial $\mathrm{KA}$-induced convulsions (Pisa et al., 1980; Calvalheiro et al., 1982).

Several lines of evidence suggest that pathways from entorhinal cortex $(E C)$ to the hippocampal formation (dentate gyrus and Ammon's horn) are critical for maintainance of KA-induced behavioral seizures and the accompanying neuropathological sequelae. Transection of entorhinal projections to the hippocampal formation attenuates convulsions and subsequent damage to pyramidal neurons of Ammon's horn induced by intra-amygdalar KA (Ben-Ari et al., 1980b). Prolonged electrical stimulation of entorhinal projections to hippocampus produces damage to pyramidal neurons (Sloviter and Damiano, 1981b). Electrical stimulation of entorhinal afferents also produces wet dog shakes (WDS) (Damiano and Connor, 1984), a behavior that precedes KA-induced seizures (Lothman and Collins, 1981). Afferents to hippocampus from lateral EC consist of (1) the temporoammonic path, originating in the pyramidal cells of the deeper layers of the $\mathrm{EC}$ and projecting to the stratum lacunosum moleculare of Ammon's horn, and (2) the perforant path originating in the stellate cells of the superficial layers of EC and projecting to the outer molecular layer of the dentate gyrus (Steward and Scoville, 1976; Swanson and Köhler, 1986). The relative importance of these pathways in the propagation of WDS, seizures, and subsequent seizure-related cell loss has yet to be determined. In this study, we selectively lesioned the granule cells of the dentate gyrus with colchicine (COL) (Goldschmidt and Steward, 1980), a neurotoxin that acts by blocking axonal transport (Lothman et al., 1982; Steward et al., 1984), and observed the effects on WDS, seizures, and the neuropathological sequelae of seizures induced by systemic administration of KA.

\section{Materials and Methods}

Animals. Male Fischer-344 rats (Charles River, Wilmington, MA) were fed ad libitum and housed in a room maintained at $21 \pm 2^{\circ} \mathrm{C}$ and $50 \pm$ $10 \%$ humidity on a $12 / 12 \mathrm{hr}$ light/dark cycle.

Treatment of animals. Rats between 15 and 16 weeks of age were anesthetized with pentobarbital $(50 \mathrm{mg} / \mathrm{kg})$ and placed in stereotaxic holders (David Kopf Instruments, Tujunga, CA). Thirty rats were given bilateral injections of COL (Sigma Chemical Co., St. Louis, MO; 2.5 $\mu \mathrm{g}$ in $0.5 \mu \mathrm{l}$ of physiological saline per site) into dorsal, medial, and ventral hippocampus. Twenty-seven rats were given injections of equivalent volumes of physiological saline (SAL), and 3 rats were injected with dye and killed immediately in order to verify stereotaxic coordinates. In the skull flat position (Paxinos and Watson, 1982), injections were made at the following coordinates: 


\begin{tabular}{lccc} 
Site & $\begin{array}{c}\text { Posterior } \\
\text { to bregma }\end{array}$ & $\begin{array}{c}\text { Lateral to } \\
\text { midline }\end{array}$ & $\begin{array}{c}\text { Ventral } \\
\text { to bregma }\end{array}$ \\
\hline Dorsal & $3.3 \mathrm{~mm}$ & $2.5 \mathrm{~mm}$ & $4.0 \mathrm{~mm}$ \\
Medial & $5.8 \mathrm{~mm}$ & $4.5 \mathrm{~mm}$ & $5.5 \mathrm{~mm}$ \\
Ventral & $5.8 \mathrm{~mm}$ & $4.5 \mathrm{~mm}$ & $7.0 \mathrm{~mm}$
\end{tabular}

Injections were made at a rate of $0.1 \mu \mathrm{l} / \mathrm{min}$ using a $1.0 \mu \mathrm{l}$ Hamilton syringe and a manually operated microinjector (David Kopf Instruments). Needles were left in place for $2.0 \mathrm{~min}$ to allow diffusion of fluid away from the site. After surgery, rats were housed individually and were allowed 2 weeks to recover.

Of the 53 (28 COL, $25 \mathrm{SAL}$ ) rats that survived the recovery period, 27 were injected subcutaneously with KA (Sigma; $8 \mathrm{mg} / \mathrm{kg}$ body weight), and the remaining 26 were injected with equivalent volumes of SAL. The number of WDS and seizures exhibited over the $2.5 \mathrm{hr}$ observation period was recorded by observers who had no knowledge of the prior treatment of the rats. Seizure onset was defined as the first occurrence of facial and forelimb clonus with rearing. Seizures were terminated with pentobarbital $(50 \mathrm{mg} / \mathrm{kg}) 1 \mathrm{hr}$ after onset to prevent death; SALtreated rats were given equivalent doses of pentobarbital $2.5 \mathrm{hr}$ after the SAL injection. Rats were killed $48 \mathrm{hr}$ after KA injection. For radioimmunoassay of methionine-enkephalin (ME) and dynorphin (DYN) A (1-8), 27 rats were decapitated and their brains quickly removed from the skull; hippocampus (dissected into dorsal and ventral halves) and EC (including both lateral and medial portions) were frozen on dry ice and stored at $-70^{\circ} \mathrm{C}$. For routine histological studies, 9 rats were anesthetized with pentobarbital and gravity-perfused through the heart with $100 \mathrm{ml}$ of $0.9 \%(\mathrm{wt} / \mathrm{vol})$ saline, followed by $200 \mathrm{ml}$ of $5 \%(\mathrm{wt} / \mathrm{vol})$ paraformaldehyde in phosphate buffer at $4^{\circ} \mathrm{C}$. For Timm's and immunocytochemical studies, 10 rats were perfused with $200 \mathrm{ml}$ of $1.17 \%$ $(\mathrm{wt} / \mathrm{vol}$ ) sodium sulfide in phosphate buffer, followed by $200 \mathrm{ml}$ of $5 \%$ paraformaldehyde. Brains were dissected and stored in $5 \%$ paraformaldehyde for $3 \mathrm{hr}$ and then transferred to $15 \%(\mathrm{wt} / \mathrm{vol})$ sucrose in PBS for cryoprotection against frozen sectioning.

Radioimmunoassay (RIA). Tissue levels of ME and DYN were determined as described previously for $\beta$-endorphin (Hong et al., 1984). Briefly, frozen tissue was homogenized in $2 \mathrm{~N}$ acetic acid, immersed in boiling water $(5 \mathrm{~min})$, cooled over ice, and centrifuged $(25,000 \times g$ for $20 \mathrm{~min}$ at $4^{\circ} \mathrm{C}$ ). The supernatant was lyophilized, and the dry residue reconstituted in RIA buffer. The mixture was clarified by centrifugation, and aliquots of the supernatant combined with RIA buffer, antiserum, and ${ }^{125} \mathrm{I}$-labeled peptide $(10,000 \mathrm{cpm})$. Samples and standard peptide dilutions were incubated for $16-24 \mathrm{hr}$ at $4^{\circ} \mathrm{C}$; charcoal slurry $(3 \%)$ was added to adsorb unbound peptide, and bound peptide was separated from unbound peptide by centrifugation $\left(3000 \times g\right.$ at $\left.4^{\circ} \mathrm{C}\right)$. Aliquots of the supernatant were counted in a gamma counter and compared to those of the standards. Antiserum for ME (ME-731; a gift from W. Hendrin, Research Triangle Institute) cross-reacts with other peptides as follows: leucine-enkephalin (LE), $0.98 \%$; DYN A (1-8), $<0.06 \%$; Met $^{5}$-enkephalin-Arg ${ }^{6}-\mathrm{Phe}^{7}, 0.42 \%$. Antiserum for DYN A (1-8) (DYN1 , prepared in this laboratory) cross-reacts with related peptides as follows: ME, <0.0005\%; LE, <0.0005\%; DYN A (1-13), 0.02\%; DYN A (1-17), $0.01 \%$.

Immunocytochemistry. The immunocytochemical methods used have been described by McGinty et al. (1983, 1984). Briefly, 4 serial $50 \mu \mathrm{m}$ sections were cut on a freezing microtome at $400 \mu \mathrm{m}$ intervals throughout the hippocampus. Two adjacent sections in a series were incubated with $2 \%$ Triton X-100 in $10 \mathrm{~mm}$ PBS for $5 \mathrm{~min}$; next, they were rinsed for $30 \mathrm{~min}$ in PBS and incubated $48-72 \mathrm{hr}$ at $4^{\circ} \mathrm{C}$ with antiserum to DYN A (1-17) (a gift of Lars Terenius, Uppsala, Sweden), diluted 1:1000 (McGinty et al., 1983), or with ME (ME-13; Kanamatsu et al., 1986), diluted 1:1500. Sections were rinsed 3 times with PBS and incubated for $1 \mathrm{hr}$ in biotinylated goat anti-rabbit IgG (Vectastain; Vector Labs, Burlingame, CA). After 3 rinses in PBS, sections were placed in a solution of avidin-biotin-HRP complex (Vectastain) for $1 \mathrm{hr}$. Sections were rinsed 3 times with PBS and incubated for 8-10 min with $0.05 \%$ 3',3'-diaminobenzidine tetrahydrochloride (Electron Microscopy Sciences, Fort Washington, PA) in $0.05 \mathrm{~m}$ phosphate buffer with $0.003 \%$ $\mathrm{H}_{2} \mathrm{O}_{2}$. The sections were mounted on gelatin/chromalum-coated slides and coverslipped with Permount.

One of the remaining hippocampal sections was processed for the Timm sulfide silver stain to visualize the presence of heavy metals (Timm, 1958). The final section was treated with a Nissl stain (Richardson et al., 1960); Timm's-treated sections were also counterstained using Richardson's method (Richardson et al., 1960).

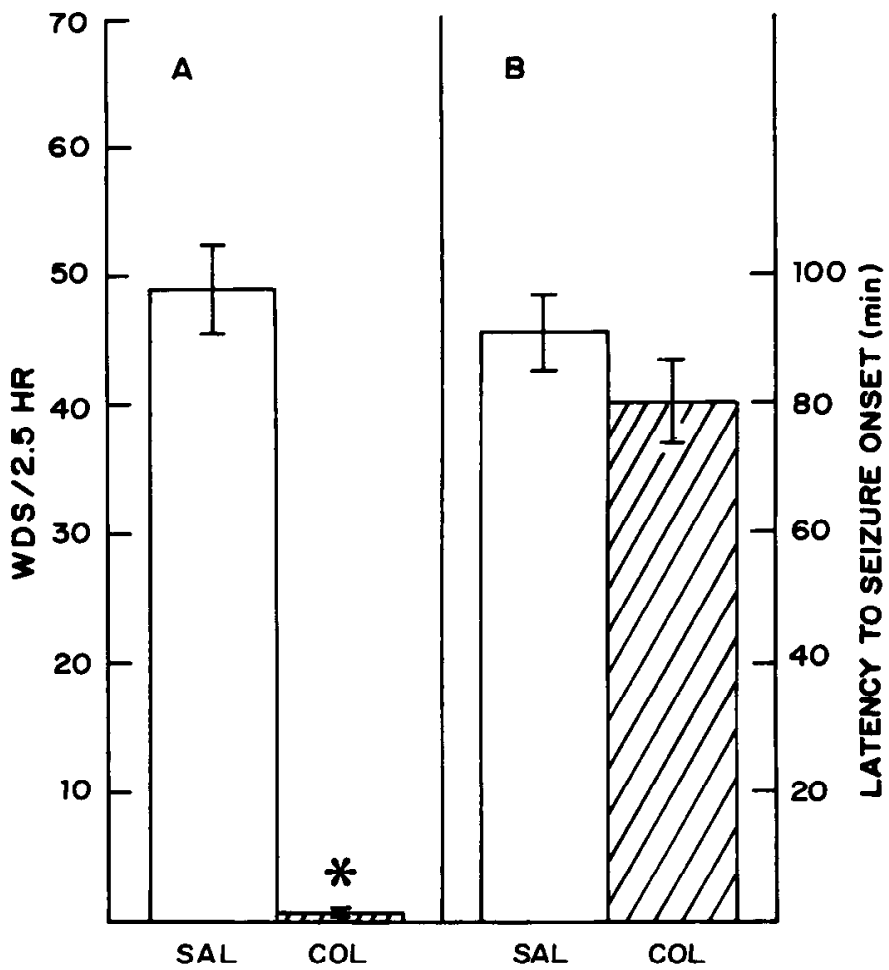

Figure 1. Kainic acid (KA)-induced wet dog shakes (WDS) and seizure onset. $A$, Colchicine (COL) lesions eliminated WDS $(p<0.0001) . B$, COL lesions had no effect on the latency to onset of behavioral seizures.

Histology. For routine histology, two $3 \mathrm{~mm}$ blocks cut in the coronal plane from 1 to $7 \mathrm{~mm}$ posterior to bregma were placed in a Tissue Tek III vacuum infiltration processor to be dehydrated through graduated concentrations of alcohol-water $(80-100 \%)$; they were then cleared with xylene and impregnated with paraffin. These blocks were cut in $10 \mu \mathrm{m}$ sections, and every fifth section was mounted on a slide and heated overnight at $45^{\circ} \mathrm{C}$. The sections were stained with Luxol fast blue and counterstained with cresyl echt violet (Klüver and Barrera, 1953).

The width of granule and pyramidal cell layers (WGCL and WPCL, respectively) was measured by modifying a previously published method (Dyer et al., 1982). Coronal sections 3.8 and $6.3 \mathrm{~mm}$ posterior to bregma were selected for each animal. Photomicrographs $(50 \times)$ were made of the following sites in dorsal hippocampus: (1) the dorsal blade of the dentate granule cell layer approximately $1.5 \mathrm{~mm}$ lateral to midline, (2) the CA1 pyramidal cell layer $1.5 \mathrm{~mm}$ lateral to midline, and (3) the CA3 pyramidal cell layer at the point of maximum curvature, approximately $4.5 \mathrm{~mm}$ lateral to midline. The following areas were photographed in the ventral hippocampus at approximately $7.0 \mathrm{~mm}$ below the surface of the skull: (1) the lateral blade of the dentate (continuation of the dorsal blade), (2) the CA1 pyramidal layer, and (3) the CA3 pyramidal cell layer. A photomicrograph of a stage micrometer $(50 \times)$ was used to measure the width of cell layers on $3 \times 5$ in. enlargements. In cell layers with contiguous cell bodies, measurements were made directly; in layers with noncontiguous cell bodies (frequently seen in treated rats), widths of individual cells were measured and added. Three measurements $100 \mu \mathrm{m}$ apart were made on each side of the brain, and were averaged to give a single value for dorsal or ventral hippocampus. Only measurements from those rats for which the requisite sections from both dorsal and ventral hippocampus were available were used in the analyses.

Statistics. Between-group comparisons were made for Lesion (COL vs SAL) and Drug (KA vs SAL); the within-subject comparison was for the Hippocampal region (Dorsal vs Ventral). The dependent measures in these analyses were hippocampal weight, ME, DYN, WGCL, WPCL at CA1, and WPCL at CA3. Separate analyses for the interactive effects of KA and COL were carried out for rats that exhibited seizures and for those that did not. All rats submitted for histological and immunocytochemical procedures exhibited behavioral seizures. Values for ME in EC were analyzed using the 2 between-group factors given above. 

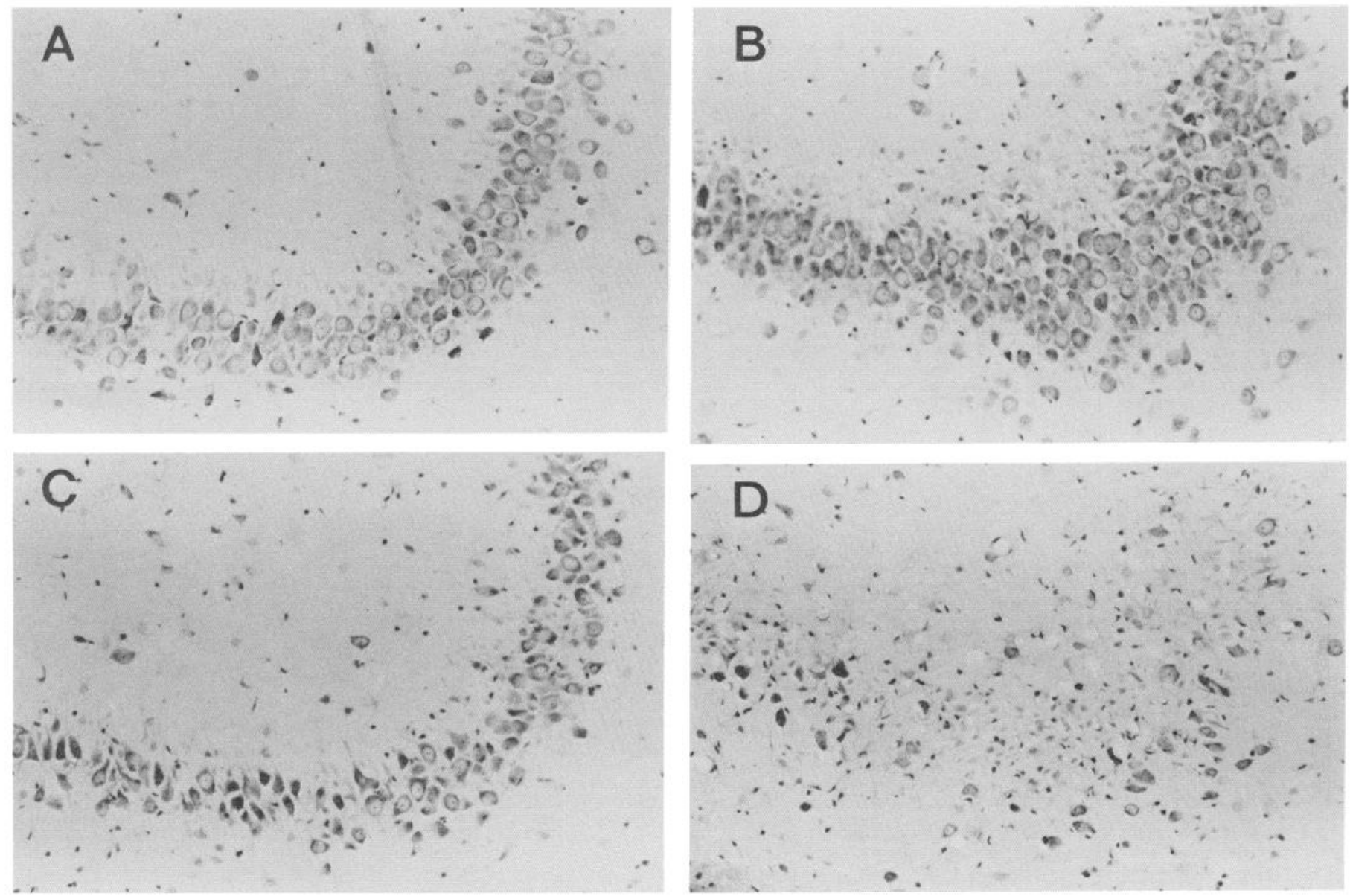

Figure 2. Nissl staining of the CA3 cell layer in dorsal hippocampus. Sections from SAL-SAL- $(A)$, SAL-KA- $(B)$, COL-SAL- $(C)$, and COL$\mathrm{KA}-(D)$ treated rats. $\times 200$.

Behavioral measures were recorded only for those rats treated with KA; the single factor involved in these analyses was Lesion (COL vs SAL). Dependent behavioral measures analyzed were total WDS observed during the $2.5 \mathrm{hr}$ following $\mathrm{KA}$ administration and latency to onset of behavioral seizures. Significance of differences was determined with analysis of variance (ANOVA). Significant ANOVAs for main effects were followed by Scheffé's test, using the appropriate pooled error term. The $\alpha$ level was set at a $p$ value of 0.05 .

\section{Results}

\section{Behavior}

COL lesions eliminated KA-induced WDS $(F(1,25)=75.26$, $p<0.0001$ ) (Fig. 1A). Eight of 13 COL-lesioned rats exhibited the full range of KA-induced behavioral seizures (facial and forelimb clonus, hypersalivation, rearing, falling, and eventual status epilepticus), whereas all SAL-lesioned rats had seizures. The latency to onset of behavioral seizures was the same for COL- and SAL-injected rats $(F(1,20)=1.51, p>0.05)$ (Fig. $1 B)$. The remaining $5 \mathrm{COL}$-lesioned rats exhibited no behavioral signs after KA injection.

\section{Hippocampal weight}

KA had no effect on hippocampal weight $(F(1,23)=0.71, p=$ $0.4094)$, but COL caused a $40 \%$ decrease $(F(1,23)=132.65$, $p<0.0001)$; this effect was slightly greater in ventral than in dorsal hippocampus $(F(1,23)=4.69, p=0.0410)$. KA did not alter the COL-induced changes in hippocampal weight $(F(1,23)=$ $3.83, p=0.0620)$.

\section{Histology}

Information concerning the statistical significance of main treatment effects and interactions for these and all other tests is given in Table 1. The WGCL and WPCL were constant throughout hippocampus (Table 2). KA alone did not affect WGCL; COL alone caused $61 \%$ decrease; and combined COL and KA caused an $80 \%$ decrease (Table 2). KA caused a nonsignificant $23 \%$ decrease in WPCL in CA1; COL alone had no effect; and combined COL and KA caused a $40 \%$ decrease that was not statistically significant (Table 2). KA alone caused a nonsignificant $30 \%$ decrease in the WPCL in CA3; COL alone had no effect; and combined COL and KA caused a 77\% decrease in WPCL in CA3 (Table 2, Fig. 2).

KA had no effect on Timm's staining. COL alone greatly reduced or eliminated staining in mossy fiber axons and attenuated staining in projections from entorhinal cortex to dentate. In rats subjected to combined COL and KA treatments, Timm's staining in the projections from EC to dentate was observed in some rats (Fig. 3, $C, D$ ) but not in others.

\section{Radioimmunoassay and immunocytochemistry}

Methionine-enkephalin (ME). ME in ventral hippocampus was approximately 3 times that in dorsal hippocampus (Table 3 ). KA alone caused a $165 \%$ increase in hippocampal ME, and COL alone caused a nonsignificant $58 \%$ decrease in ME (Table $3)$. In rats that exhibited seizures, COL attenuated the KA- 
Table 1. Analyses for the effects of colchicine and kainic acid

Effect

Drug: SAL vs KA

Hipp. ME

Ent. ME

Hipp. DYN

Hipp. WT

WGCL

WPCL CAI

WPCL CA3

Lesion: SAL vs COL

Hipp. ME

Ent. ME

Hipp. DYN

Hipp. WT

WGCL

WPCL CA1

WPCL CA3

Drug $\times$ lesion

Hipp. ME

Ent. ME

Hipp. DYN

Hipp. WT

WGCL

WPCL CAl

WPCL CA3

Drug $\times$ lesion: seizures

Hipp. ME

Ent. ME

Drug $\times$ lesion: no seizures

Hipp. ME

Ent. ME

Region: dors. vs vent.

Hipp. ME

Hipp. DYN

Hipp. WT

WGCL

WPCL CA 1

WPCL CA3

Region $\times$ drug

Hipp. ME

Hipp. DYN

Hipp. WT

WGCL

WPCL CA 1

WPCL CA3

Region $\times$ lesion

Hipp. ME

Hipp. DYN

Hipp. WT

WGCL

WPCL CA 1

WPCL CA3

Reg. $\times$ les. $\times$ drug

Hipp. ME

Hipp. DYN

Hipp. WT

WGCL

WPCL CAl

WPCL CA3
F

$d f$

$p$

$<0.0001$

5.28

56.37

70.18

1.30

124.83

132.65

149.02

1.32

11.67

21.24

0.03

11.19

3.83

5.14

0.09

10.26

7.53

4.74

41.68

2.40

113.09

36.10

0.98

1.17

1.16

0.66

9.71

0.48

1.25

0.16

6.71

0.44

24.01

37.46

4.69

0.24

0.65

0.32

4.53

0.30

0.00

0.01

0.31

3.59
0.0411

0.0036

0.4094

0.5265

0.0404

$<0.0001$

1,21

1,23

1,12

1,12

1,12

1,22

$<0.0001$

0.2670

$<0.0001$

$<0.0001$

$<0.0001$

0.2733

0.0051

$<0.0001$

0.8598

0.0029

0.0620

0.0426

0.7750

0.0076

1,12

1,12

0.0133

0.0439

$1,20<0.0001$

1,19

0.1379

1,22

1,22

1,23

1,12

1,12

1,12

1,22

1,22

1,23

1,12

1,12

1,12

1,22

1,22

1,23

1,12

1,12

1,12

1,22

1,22

1,23

1,12

1,12

1,12
$<0.0001$

$<0.0001$

0.3335

0.3013

0.2215

0.4326

$<0.005$

0.4939

0.2748

0.6977

0.0236

0.5190

$<0.0001$

$<0.0001$

0.0410

0.6337

0.4349

0.5819

0.0447

0.5890

0.9536

0.9379

0.5888

0.0825
Table 1. Continued

\begin{tabular}{|c|c|c|c|}
\hline Effect & $F$ & $d f$ & $p$ \\
\hline $\begin{array}{l}\text { Reg. } \times \text { les. } \\
\text { Hipp. ME }\end{array}$ & 0.15 & 1,18 & 0.7060 \\
\hline \multicolumn{4}{|c|}{ Reg. $\times$ les. $\times$ drug: no seiz } \\
\hline Hipp. ME & 12.98 & 1,20 & 0.0018 \\
\hline
\end{tabular}

induced increase in $\mathrm{ME}$ in ventral hippocampus (values were significantly greater than in SAL-COL or nonseizing COL-KA rats but significantly less than in SAL-KA rats), whereas in rats that did not have scizures, ME in ventral hippocampus was significantly less than in SAL-SAL controls (Table 3). ME in dorsal hippocampus was reduced in all COL-treated rats, but the reductions $(53-64 \%)$ were not significant.

In $\mathrm{EC}, \mathrm{KA}$ alone caused an $80 \%$ increase in $\mathrm{ME}$ that was not significant, and COL alone did not reduce levels of ME (Table 3). In COL-lesioned rats exhibiting seizures, KA caused a $182 \%$ increase in $\mathrm{ME}$, an increase greater than that caused by KA alone. In COL-lesioned rats that did not exhibit seizures, entorhinal ME did not differ from values in COL-lesioned rats not exposed to KA or from those of SAL-SAL controls (Table 3).

In SAL-SAL-treated rats, immunostaining for ME in mossy fibers was light (Fig. 4A), as described previously (Gall et al., 1981; McGinty et al., 1983). KA caused an expected increase in ME staining in mossy fibers (Fig. 4B) (Kanamatsu et al., 1986). COL caused a decrease in ME immunostaining of the temporoammonic pathway and a reduction or elimination of staining in mossy fibers (Fig. $4 C$ ). In most COL-lesioned, KAtreated rats, the perforant pathway to the dentate gyrus and the temporoammonic path remained intact, and staining appeared intensified compared to that in COL-SAL-treated rats (Fig. $4 D$ ). However, pyramidal cells in the deeper layers of the entorhinal cortex, which are not usually visualized, stained heavily in onc rat (Fig. 4, $E, F$ ), and staining in part of the temporoammonic path was reduced (Fig. $4 E$ ).

Dynorphin $(D Y N)$. Levels of DYN in ventral hippocampus

Table 2. Width of hippocampal and dentate cell layers following colchicine and/or kainate $(\mu \mathrm{m} \pm \mathrm{SEM})$

Conditions

SAL-SAL SAL-KA COL-SAL COL-KA

Granule layer

Dorsal $\quad 67 \pm 7 \quad 72 \pm 6 \quad 29 \pm 7^{* *} \quad 15 \pm 2^{* *}$

Ventral $\quad 63 \pm 6 \quad 71 \pm 5 \quad 21 \pm 10^{* *} \quad 11 \pm 4^{* *}$

Dors. + vent. $\quad 65 \pm 4 \quad 72 \pm 4 \quad 25 \pm 4^{* *} \quad 13 \pm 2^{* *}$

Pyramidal layer: CA1

Dorsal $\quad 50 \pm 5 \quad 35 \pm 7 \quad 44 \pm 3 \quad 24 \pm 3$

Ventral $\quad 47 \pm 2 \quad 40 \pm 7 \quad 43 \pm 7 \quad 35 \pm 5$

Dors. + vent. $\quad 48 \pm 2 \quad 37 \pm 5 \quad 44 \pm 4 \quad 29 \pm 3$

Pyramidal layer: CA3

$\begin{array}{lllll}\text { Dorsal } & 122 \pm 11 & 75 \pm 14 & 108 \pm 5 & 30 \pm 7^{* *} \\ \text { Ventral } & 102 \pm 6 & 81 \pm 9 & 113 \pm 5 & 23 \pm 8^{* *} \\ \text { Dors. + vent. } & 112 \pm 7 & 78 \pm 8 & 110 \pm 3 & 26 \pm 5^{* *}\end{array}$

Post hoc analyses are in reference to SAL-SAL controls.

$* * p<0.01$. 

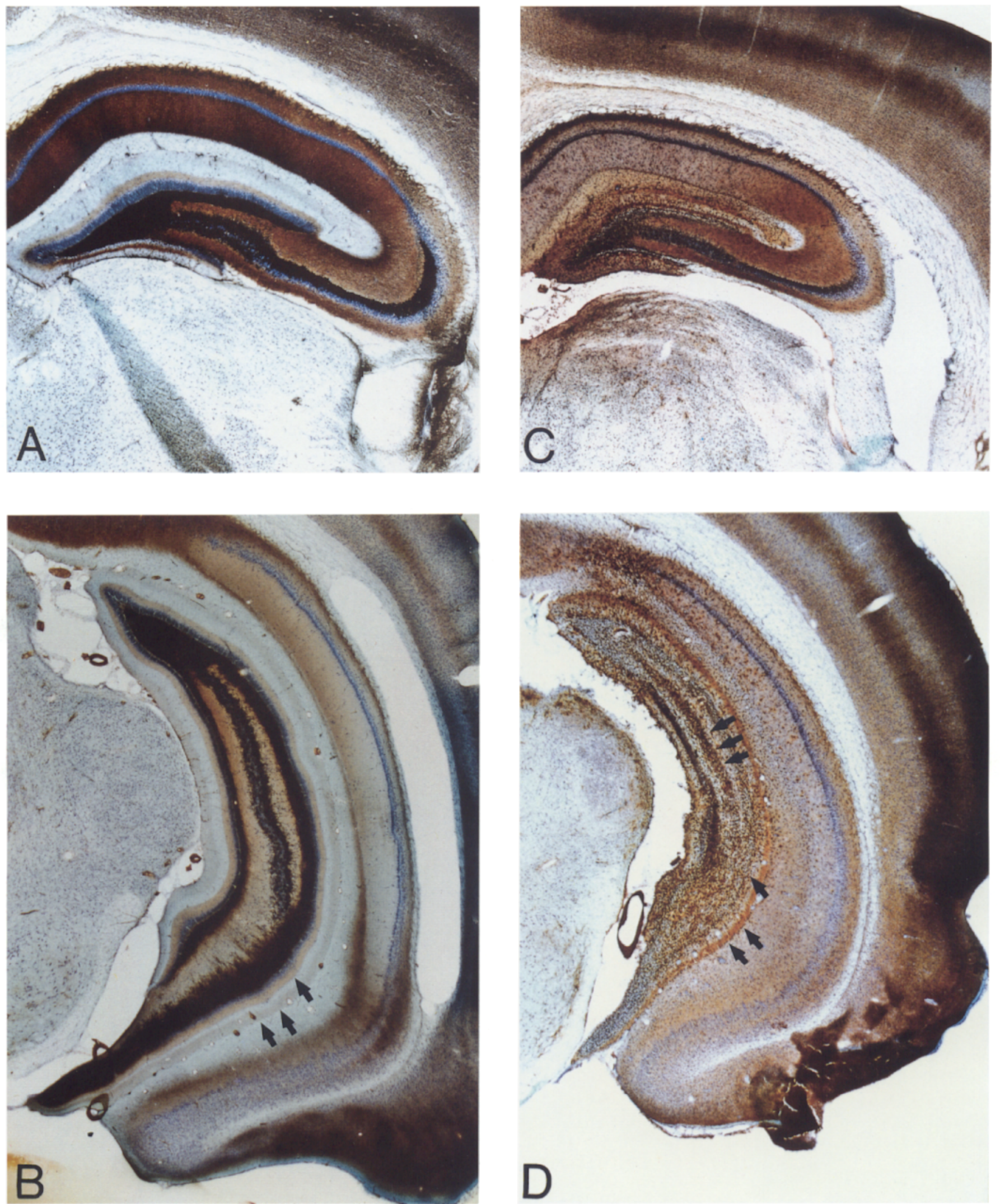

Figure 3. Timm's staining in dorsal and ventral hippocampus. Dorsal $(A)$ and ventral $(B)$ hippocampus in a SAL-SAL-treated rat. Zinc-containing mossy fiber axons of dentate granule cells stained black in the Timm sulfide silver reaction. Projections from hilar neurons to the inner molecular layer of dentate stained light brown ( 1 arrow), and perforant path projections from entorhinal cortex to the outer molecular layer of the dentate gyrus stained $\tan (2$ arrows). Dorsal $(C)$ and ventral $(D)$ hippocampus in rats with combined COL and KA treatments. COL lesions of granule cells reduced or eliminated Timm staining of mossy fiber axons and the inner molecular layer of dentate ( 1 arrow), but the perforant path to dentate remained intact ( 2 arrows). The combined COL-KA treatments caused a reduction in the CA3 cell layer ( 3 arrows), a reduction of the neuropil of dentate gyrus, and massive glial infiltration. $\times 20$. 

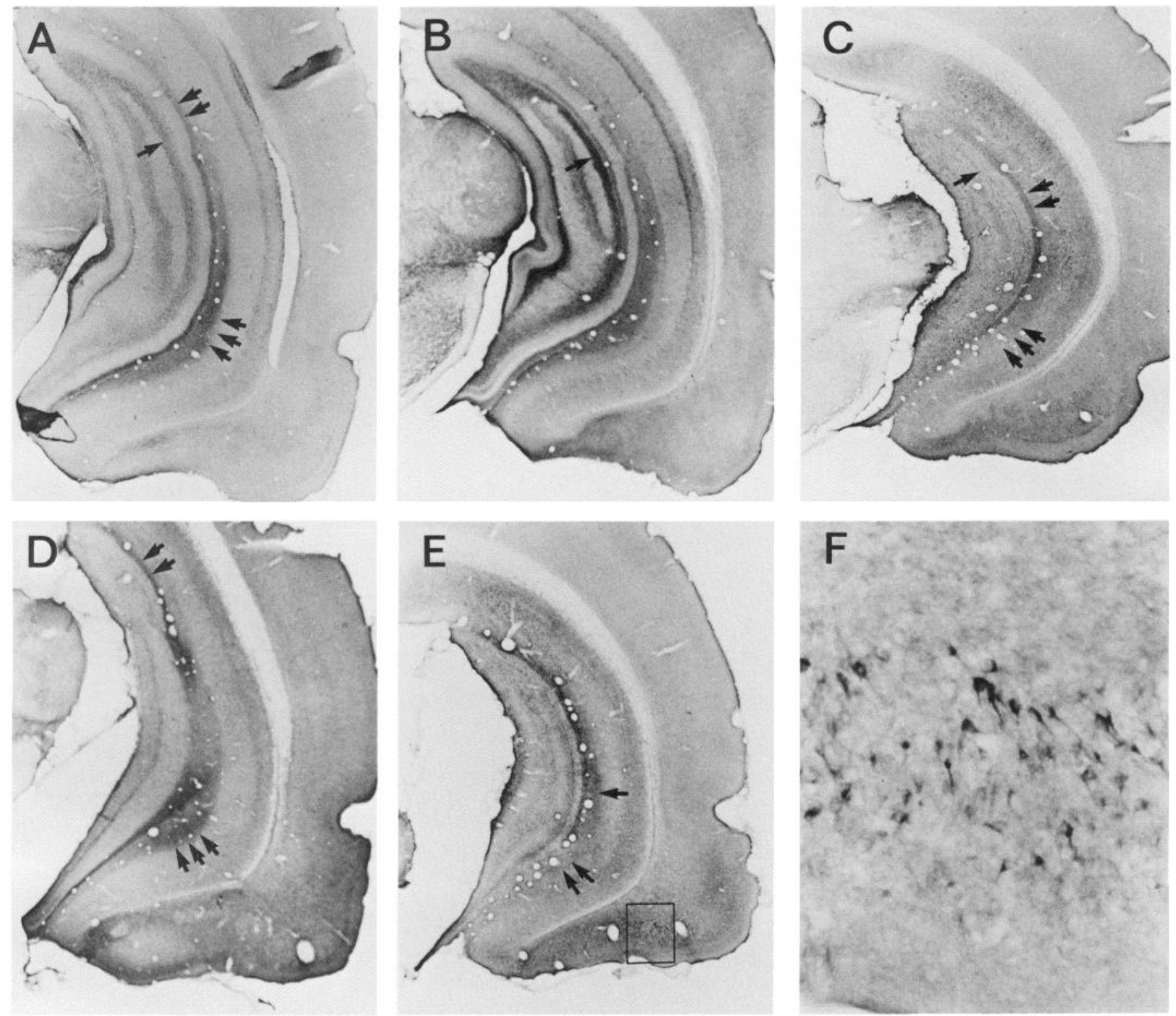

Figure 4. Immunostaining for ME in ventral hippocampus. A, Ventral hippocampus in a SAL-SAL-treated rat. $\times 17.2$. Mossy fibers (1 arrow) stained lightly. Perforant path ( 2 arrows) and temporoammonic path ( 3 arrows) staining was darker than mossy fiber staining. $B$, Ventral hippocampus in a rat treated with KA alone. Staining for ME was increased in mossy fibers $(1$ arrow $)$. $C$, Ventral hippocampus in a COL-SAL-treated rat. Staining for ME was eliminated in the mossy fibers (1 arrow), appeared intact in the perforant path to dentate ( 2 arrows), and appeared decreased in the temporoammonic path ( 3 arrows). $D$, Ventral hippocampus in a COL-KA-treated rat. Following KA administration, staining of the perforant path $(2$ arrows $)$ and the temporoammonic path ( 3 arrows $)$ was intensified compared to that in COL-SAL-treated rats. $E$, Ventral hippocampus in a COL-KA-treated rat. ME immunostaining of the dorsal part of the temporoammonic path appeared intact ( 1 arrow), but was diminished in the ventral part ( 2 arrows). Enhancement of staining of pyramidal neurons in the deeper layers of entorhinal cortex was observed (boxed area). $F$, Neurons in boxed area of $E$ are shown at higher magnification $(\times 200)$.

were twice those in dorsal hippocampus (Table 4). KA alone caused a $41 \%$ decrease in hippocampal DYN, and COL reduced hippocampal DYN in both SAL- and KA-treated rats to the limits of detection of the RIA (Table 4). KA alone caused a slight reduction in DYN immunostaining (Fig. $5, C, D$ ), and COL reduced or eliminated DYN staining in mossy fibers in both SAL- and KA-treated rats (Fig. 5, E, F).

\section{Discussion}

Three major conclusions can be drawn from this study. First, dentate granule cells appear to be essential for the expression of KA-induced WDS. Second, they do not appear to be essential for KA-induced behavioral seizures. Third, $\mathrm{COL}$ injections into hippocampus potentiate KA-induced pyramidal cell loss in Ammon's horn.

Activity passing through the dentate gyrus appears to be essential for the expression of KA-induced WDS. Electrical stimulation of the granule cells or of afferents to hippocampus from entorhinal cortex evokes WDS (Damiano and Connor, 1984), and lesions of the CA3 region of Ammon's horn, which receives input from dentate granule cells, attenuate WDS (Isaacson and Lanthorn, 1981). In our study, COL lesions that destroyed granule cells blocked KA-induced WDS.

An opiate basis for KA-induced WDS has been considered; 

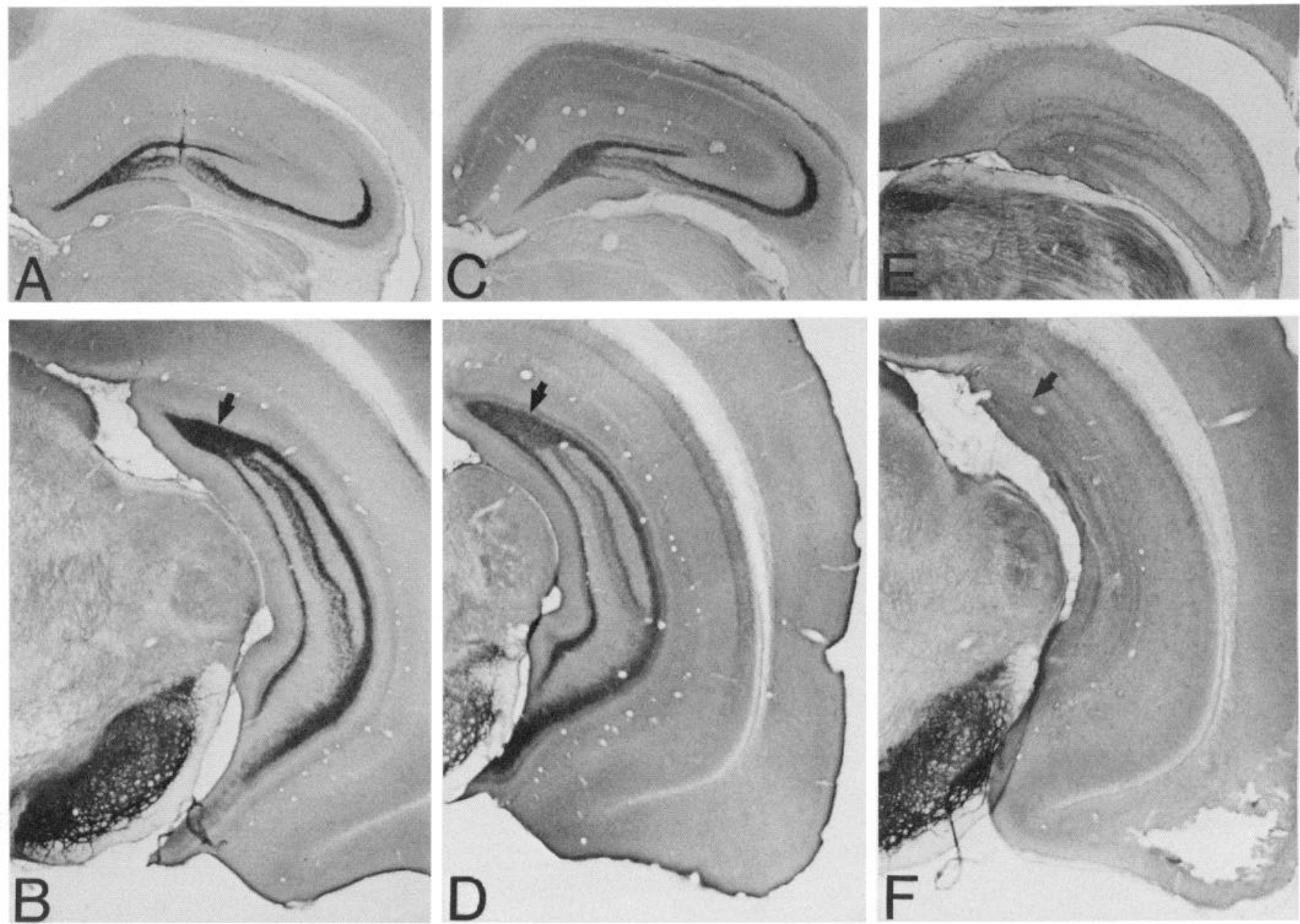

Figure 5. Immunostaining for DYN in dorsal and ventral hippocampus. $\times 15$. Dorsal $(A)$ and ventral $(B)$ hippocampus in a SAL-SAL-treated rat. Mossy fiber axons of granule cells stained intensely for DYN, as did fibers in substantia nigra projecting from caudate (arrow). Dorsal $(C)$ and ventral $(D)$ hippocampus in a KA-treated rat. Intensity of DYN staining is slightly reduced in mossy fibers. Dorsal $(E)$ and ventral $(F)$ hippocampus in a COL-KA-treated rat. Staining for DYN was greatly reduced in mossy fibers (arrow), but remained intact in substantia nigra.

naloxone reverses WDS caused by injection of enkephalin or KA into lateral ventricles (Lanthorn and Isaacson, 1978; Drust and Connor, 1983). If release of enkephalin within the hippocampus does play a major role in the induction of WDS, it seems likely that this release is either from entorhinal afferents onto functionally intact granule cells or from the axons of granule cells onto CA3 pyramidal neurons.

Most COL-lesioned rats exhibited behavioral seizures that were identical to those of SAL-lesioned rats in morphology, intensity, and time of onset. The COL-lesioned rats exhibiting

Table 3. Hippocampal and entorhinal ME following colchicine and/or kainate (pg/10 mg wet weight \pm SEM)

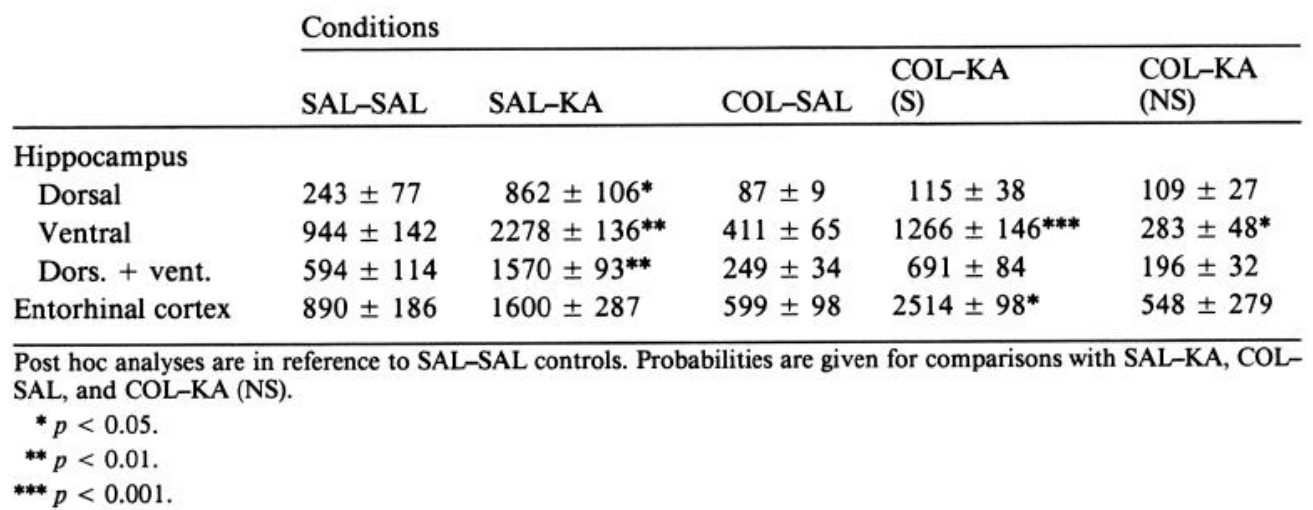


seizures had a greater than $90 \%$ reduction in hippocampal DYN, which is contained only in dentate granule cells (McGinty et al., 1983 ); an $80 \%$ reduction in the width of the granule cell layer; marked atrophy of the dentate; and an elimination of staining for ME, DYN, or Timm's reaction in mossy fiber axons. These findings suggest that dentate granule cells are not essential for seizures induced by systemic administration of $\mathrm{KA}$.

However, several COL-lesioned rats did not have seizures following KA. Monmaur and Thomson (1986) and Lothman et al. (1982) have reported that single injections of COL (2.0-2.4 $\mu \mathrm{g})$ damage pyramidal neurons in some treated rats. In rats with damage to pyramidal cells, theta rhythm is disrupted, whereas in rats with damage limited to granule cells, theta is unaffected. In subsequent studies in this laboratory, we have found that 1.0 $\mu \mathrm{g}$ doses of $\mathrm{COL}$ injected into ventral hippocampus 1,2 , or 3 d prior to $\mathrm{KA}$ administration totally disrupt seizures, whereas WDS are reduced more gradually, diminishing by $42 \%$ on day $1,66 \%$ on day 2 , and $90 \%$ by day 3 . However, single doses of $\mathrm{COL}$, ranging from 0.5 to $2.0 \mu \mathrm{g}$, given 2 weeks prior to $\mathrm{KA}$ eliminate WDS but have no effect on behavioral seizures (L. M. Grimes, unpublished observations). These findings of differential, time-dependent effects of COL on seizures and WDS are paralleled by studies showing that microtubules in pyramidal cells are initially disaggregated, but that the cells later recover, whereas microtubules in granule cells are disaggregated and the cells eventually die (Steward et al., 1984).

Although low doses of COL cause widespread destruction of granule cells, thereby preventing transmission through the dentate, entorhinal afferents to Ammon's horn remain intact, leaving open the possibility that this pathway may be responsible for the maintainence of recurrent activity through the limbic system. In support of this hypothesis is the finding that KAinduced seizures damage cell bodies of origin of the temporoammonic path, but not of the perforant path to dentate (Nadler et al., 1980).

Lesions of granule cells have been reported to prevent CA3 cell loss following intracerebroventricular (icv), but not intrahippocampal, administration of KA (Nadler and Cuthbertson, 1980). Both methods of administration appear to provide for a direct neurotoxic effect of KA on CA3 pyramidal neurons, because CA 3 cell loss cannot be blocked by lesions of entorhinal cortex (Nadler and Cuthbertson, 1980) or by pretreatment with benzodiazepines (Ben-Ari et al., 1980b). COL injected $3 \mathrm{~d}$ prior to icv KA (at a time when the authors report a decrease in Nissl staining of pyramidal neurons) may prevent KA-induced CA3 cell death by blocking axonal transport and preventing uptake of $\mathrm{KA}$ into hippocampus.

In contrast, systemic KA combined with $\mathrm{COL}$ injections into hippocampus markedly reduces the width of the CA3 pyramidal cell layer compared to that in SAL-injected rats. The mechanism by which COL lesions potentiate CA3 pyramidal cell loss after systemic KA is unclear. COL may simply increase the fragility of pyramidal neurons. However, Nakagawa et al. (1987) have reported a more than 2 -fold increase in maximal binding capacity of glutamate without an increase in binding of $\beta$-adrenergic or muscarinic cholinergic receptor ligands $12 \mathrm{~d}$ after COL injections. The persistence of this increase (up to $30 \mathrm{~d}$ postlesion) (Nakagawa et al., 1987) argues that removal of the granule cells, which putatively use glutamate as a neurotransmitter (Ottersen and Storm-Mathisen, 1985), may cause an up-regulation of glutamate receptors.

In summary, our data indicate that dentate granule cells are
Table 4. Hippocampal and entorhinal DYN following colchicine and/or kainate (pg/10 $\mathrm{mg}$ wet weight \pm SEM)

\begin{tabular}{lcccc}
\multicolumn{5}{l}{ Conditions } \\
\cline { 2 - 5 } & SAL-SAL & SAL-KA & COL-SAL & COL-KA \\
\hline Hippocampus & $89 \pm 8$ & $41 \pm 7^{*}$ & $12 \pm 1^{* *}$ & $14 \pm 1^{* *}$ \\
$\quad$ Dorsal & $183 \pm 35$ & $118 \pm 12^{*}$ & $12 \pm 1^{* *}$ & $12 \pm 1^{* *}$ \\
Ventral & $136 \pm 18$ & $80 \pm 9^{*}$ & $12 \pm 1^{* *}$ & $13 \pm 1^{* *}$ \\
Dors. + vent. &
\end{tabular}

Post hoc analyses are in reference to SAL-SAL controls.

$* p<0.05$

$* * p<0.01$.

important for the expression of KA-induced WDS. In most rats, elimination of granule cells did not attenuate the expression of behavioral seizures, suggesting that seizure propagation may occur along other routes. COL-induced damage to other neuronal populations may have prevented seizures in the remaining rats. Finally, COL injections into hippocampus potentiated KAinduced pyramidal cell loss. Although this potentiation may have been due to a COL-induced increase in pyramidal cell fragility, it is also possible that granule cell removal causes an up-regulation of glutamate binding sites and predisposes CA3 neurons to the neurotoxic effects of KA, which binds with high affinity in the stratum lucidum (Monoghan et al., 1985).

\section{References}

Ben-Ari, Y. (1985) Limbic seizure and brain damage produced by kainic acid: Mechanisms and relevance to human temporal epilepsy. Neuroscience 14: 375-403.

Ben-Ari, Y., E. Tremblay, and O. P. Ottersen (1980a) Injection of kainic acid into the amygdaloid complex of the rat: An electrographic clinical and histological study in relation to the pathology of epilepsy. Neuroscience 5: 515-528.

Ben-Ari, Y., E. Tremblay, O. P. Ottersen, and B. S. Meldrum (1980b) The rolc of epilcptic activity in hippocampal and "remote" cerebral lesions induced by kainic acid. Brain Res. 191: 79-97.

Calvalheiro, E. A., D. A. Riche, and G. Le Gal La Salle (1982) Longterm effects of intrahippocampal kainic acid injections in rats: A method for inducing spontaneous recurrent seizures. Electroenceph. Clin. Neurophysiol. 53: 581-589.

Dam, A. M. (1980) Epilepsy and neuron loss in the hippocampus. Epilepsia 21: 617-629.

Damiano, B. P., and J. D. Connor (1984) Hippocampal mediation of shaking behavior induced by electrical stimulation of the perforant path in the rat. Brain Res. 308: 383-386.

Drust, E. G., and J. D. Connor (1983) Pharmacological analysis of shaking behavior induced by enkephalins, thyrotropic-releasing hormone or serotonin in rats: Evidence for different mechanisms. J Pharmacol. Exp. Ther. 224: 148-224.

Dyer, R. S., T. L. Deshields, and W. F. Wonderlin (1982) Trimethyltin-induced changes in gross morphology of the hippocampus. Neurobehav. Toxicol. Teratol. 4: 141-147.

Gall, C., N. Brecha, K.-J. Chang, and H. J. Karten (1981) Localization of enkephalin-like immunoreactivity to identified axonal and neuronal populations of the rat hippocampus. J. Comp. Neurol. 198: 335-350.

Gastaut, H. (1980) L'épilepsie temporale. Une nouvelle étude critique après un quart de siècle. Concours Med. 15: 1-48.

Gastaut, H., J. L. Gastaut, G. E. Goncalvez Silva, and G. P. Fernandez Sanchez (1975) Relative frequency of different types of epilepsy: A study employing the classification of the international league against epilepsy. Epilepsia 16: 457-461.

Goldschmidt, R. B., and O. Steward (1980) Preferential ncurotoxicity of colchicine for granule cells of the dentate gyrus of the adult rat. Proc. Natl. Acad. Sci. USA 77: 3047-3051.

Hong, J. S., K. Yoshikawa, and R. W. Hedren (1984) Measurement 
of $\beta$-endorphin and enkephalins in biological tissues and fluids. In Methods in Enzymology, M. Conn, ed., pp. 547-564, Academic, New York.

Isaacson, R. L., and T. H. Lanthorn (1981) Hippocampal involvement in the pharmacological induction of withdrawal-like behaviors. Fed. Proc. 40: 1508-1512.

Kanamatsu, T., J. Obie, L. Grimes, J. F. McGinty, K. Yoshikawa, S. Sabol, and I. S. Hong (1986) Kainic acid alters the metabolism of Met'-enkephalin and the level of dynorphin $A$ in the rat hippocampus. J. Neurosci. 6: 3094-3102.

Klüver, H., and E. Barrera (1953) A method for the combined staining of cells and fibers in the central nervous system. J Neuropathol. Exp. Neurol. 12: 400-406.

Lanthorn, T., and R. L. Isaacson (1978) Studies of kainate-induced wet dog shakes in the rat. Life Sci. 22: 171-178.

Lothman, E. W., and R. C. Collins (1981) Kainic acid induced limbic seizures: Metabolic, behavioral, electroencephalographic and neuropathological correlates. Brain Res. 218: 299-318.

Lothman, E. W., D. A. Stine, G. F. Wooten, and D. K. Zucker (1982) Potential mechanisms underlying the destruction of dentate gyrus granule cells by colchicine. Exp. Neurol. 78: 293-302.

McGinty, J. F., S. J. Henriksen, A. Goldstein, L. Terenius, and F. E. Bloom (1983) Dynorphin is contained within hippocampal mossy fibers: Immunocytochemical alterations after kainic acid administration and colchicine-induced neurotoxicity. Proc. Natl. Acad. Sci. USA 80: 589-593.

McGinty, J. F., D. Van der Kooy, and F. E. Bloom (1984) The distribution and morphology of opioid peptide immunoreactive neurons in the cerebral cortex of rats. J. Neurosci. 4: 1104-1117.

Monmaur, P., and M. A. Thomson (1986) Spatial distribution of hippocampal-dentate theta rhythm following colchicine injections into hippocampal formation of the rat. Brain Res. 365: 269-277.

Nadler, J. V., and G. J. Cuthbertson (1980) Kainic acid neurotoxicity toward hippocampal formation: Dependence on specific excitatory pathways. Brain Res. 195: 47-56.

Nadler, J. V., B. W. Perry, and C. W. Cotman (1978) Intraventricular kainic acid preferentially destroys hippocampal pyramidal cells. Nature 271: 676-677.

Nadler, J. V., B. W. Perry, and C. W. Cotman (1980) Selective reinnervation of hippocampal area $\mathrm{CA} 1$ and the fascia dentata after destruction of CA3-CA4 afferents with kainic acid. Brain Res. 182: 1-9.
Nakagawa, Y., S. Nakamura, Y. Kasé, T. Noguchi, and T. Ishihara (1987) Colchicine lesions in the rat hippocampus mimic the alterations of several markers in Alzheimer's disease. Brain Res. 408: 5764.

Olney, J. W., V. Rhee, and O. L. Ho (1974) Kainic acid: A powerful neurotoxic analogue of glutamate. Brain Res. 77: 507-512.

Ottersen, O. P., and J. Storm-Mathisen (1985) Different neuronal localization of aspartate-like and glutamate-like immunoreactivities in the hippocampus of rat, guinea-pig and Senegalese baboon (Papio papio), with a note on the distribution of $\gamma$-aminobutyrate. Neuroscience 16: 589-606.

Paxinos, G., and C. Watson (1982) The Rat Brain in Stereotaxic Coordinates, Academic, New York.

Pisa, M., P. R. Sanberg, M. E. Corcoran, and H. C. Fibiger (1980) Spontaneously recurrent seizures after intracerebral injections of kainic acid in rat: A possible model of human temporal lobe epilepsy. Brain Res. 200: 481-487.

Richardson, K. D., L. Jarret, and E. H. Finke (1960) Embedding in epoxy resins for ultrathin sectioning in electron microscopy. Stain Technol. 35: 313-323.

Sloviter, R. S., and B. P. Damiano (1981a) On the relationship between kainic acid-induced epileptiform activity and hippocampal neuronal damage. Neuropharmacology 20: 1003-1011.

Sloviter, R. S., and B. P. Damiano (1981b) Sustained electrical stimulation of the perforant path duplicates kainate-induced electrophysiological effects and hippocampal damage in rats. Neurosci. Lett. 24. 279-284.

Steward, O., and S. A. Scoville (1976) Cells of origin of entorhinal cortex afferents to the hippocampus and fascia dentata of the rat. J. Comp. Neurol. 169: 347-370.

Steward, O., R. B. Goldschmidt, and T. Sutula (1984) IV. Neurotoxicity of colchicine and other tubulin-binding agents: A selective vulnerability of certain neurons to the disruption of microtubules. Life Sci. 35: 43-51.

Swanson, L. W., and C. Köhler (1986) Anatomical evidence for direct projections from entorhinal area to the entire cortical mantle in the rat. J. Neurosci. 6: 3010-3023.

Timm, F. (1958) Zur Histochemie der Schwermetalle, das SulfidSilber-Ferfahren. Z. Gesamte Inn. Med. 46: 706-711. 